\title{
Hepatocellular toxicity of oxalicumone A via oxidative stress injury and mitochondrial dysfunction in healthy human liver cells
}

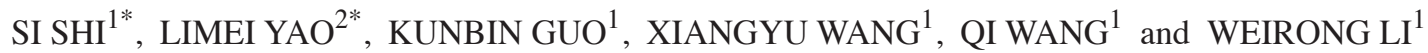 \\ ${ }^{1}$ Institute of Clinical Pharmacology, Guangzhou University of Chinese Medicine, Guangzhou, Guangdong 510405; \\ ${ }^{2}$ School of Traditional Chinese Medicine Healthcare, Guangdong Food and Drug Vocational College, \\ Guangzhou, Guangdong 510520, P.R. China
}

Received June 16, 2016; Accepted April 19, 2017

DOI: $10.3892 / \mathrm{mmr} .2017 .7979$

\begin{abstract}
The marine-derived oxalicumone A (POA) has been demonstrated as a potent anti-tumor bioactive agent for a variety of human carcinoma, but to the best of our knowledge, remains to be evaluated in healthy liver cells. As many drugs distribute preferentially in the liver, the present study aimed to investigate the effects of POA on apoptosis, oxidative stress and mitochondrial function in L-02 healthy liver cells. A Cell-Counting kit-8 assay demonstrated that POA inhibits the proliferation of L-02 cells in a dose- and time-dependent manner. Furthermore, POA induced apoptosis by increasing the percentage of cells in early apoptosis and the sub-G1 cell cycle, along with causing S-phase arrest in L-02 cells. Additionally, POA activated caspase 3, increased the protein expression levels of Fas ligand and B-cell lymphoma $\mathrm{X}$-associated protein, and decreased the expression of the anti-apoptotic protein B-cell lymphoma 2. POA additionally reduced the content of GSH and the activity of superoxide dismutase, elevated malondialdehyde and nitric oxide levels, increased reactive oxygen species production and the levels of alanine aminotransferase and aspartate aminotransferase, which suggested that POA induced lipid peroxidation injury in L-02 cells and that oxidative stress serves an important role. Furthermore, POA caused alternations of mitochondrial function, including an abrupt depletion of adenosine triphosphate synthesis, mitochondrial permeability transition pore opening and depletion of mitochondrial membrane potential in L-02 cells. These data suggested that POA exerts cytotoxicity, at least in part, by inducing oxidative stress, mitochondrial dysfunction, and eventually apoptosis. Changes
\end{abstract}

Correspondence to: $\mathrm{Dr}$ Weirong $\mathrm{Li}$, Institute of Clinical Pharmacology, Guangzhou University of Chinese Medicine, 12 Jichang Road, Guangzhou, Guangdong 510405, P.R. China E-mail: liwr@gzucm.edu.cn

${ }^{*}$ Contributed equally

Key words: cytotoxicity, L-02 cells, oxalicumone A, apoptosis, oxidative stress, mitochondrial function in mitochondrial function and oxidative stress by POA may therefore be critical in POA-induced toxicity in L-02 cells.

\section{Introduction}

The study and development of a novel drug is not only costly and time-consuming, but the safety and efficacy must be seriously considered, and determine the success of the drug. Thus, toxicity is one of the main reasons leading to the failure of drug development. The liver is considered as the most important organ in drug toxicity for as it is functionally interposed between the site of absorption and the systemic circulation, and is a major site of metabolism and elimination of foreign substances. However, these features also render it a preferred target for drug toxicity (1). Drug-induced liver injury is one of the most common reasons that accounts for the attrition of candidate drugs during the later stages of drug development (2). Consequently, early detection of drug-induced hepatotoxicity is essential before compounds are tested in animals and enter clinical trials, to save time and resources (3).

Natural product extracts have long been implemented as therapeutics all over the world (4). Since the discovery of penicillin, which was the first pure antibiotic isolated from the fungus Penicillium rubens, the industry for natural products developed in 1928 (5). The ocean covers $>70 \%$ of the earth's surface, and the marine environment is home to a taxonomically diverse ecosystem full of bioactive natural products from diverse sources as microorganisms, invertebrates, plants and animals (6). Organisms such as algae, mollusks, sponges, corals and tunicates have evolved to survive the high concentrations of infectious and surface-fouling bacteria that are indigenous to ocean waters. Marine microorganism has been recognized as a rich source of biological macromolecules and the search for bioactive compounds from marine organisms in recent decades has produced an abundance of extracts with pharmaceutical and industrial applications, such as food, cosmetics and pharmacology (7).

Oxalicumone A(POA) is a constituent isolated from aculture broth of the South China Sea fungus Penicillium oxalicum SCSGAF 0023 (8). Its chemical structure was first identified by Zhang et al (9) (Fig. 1). POA demonstrates significant cytotoxicity against several human carcinoma cell lines with $\mathrm{IC}_{50} \leq 10 \mu \mathrm{M}(8)$; therefore, it represents a potent anticancer 
bioactive agent. However, to the best of our knowledge, the influence of POA on healthy human cells remains to be investigated.

Therefore, the present study aimed to investigate the cytotoxic effects of POA on L-02 healthy human liver cells, and the underlying mechanisms, including apoptosis pathways, oxidative stress and mitochondrial function.

\section{Materials and methods}

Chemicals. RPMI 1640 medium and fetal bovine serum (FBS) were purchased from Biological Industries USA (Cromwell, CT, USA) and Biological Industries Israel Beit-Haemek (Kibbutz Beit-Haemek, Israel), respectively. Cell Counting kit-8 (CCK-8) dye was purchased from Dojindo Molecular Technologies, Inc. (Kumamoto, Japan). Trypsin, dimethyl sulfoxide (DMSO) and Hoechst 33258 were purchased from Sigma-Aldrich; Merck KGaA (Darmstadt, Germany). The Annexin V-fluorescein isothiocyanate (FITC)/propidium iodide(PI) double staining kit, cell cycle kit, 5,5,6,6-tetra-chloro-1,1,3,3-tetraethylbenzimidazolyl-carbocyanine iodide (JC-1) dye and caspase-3 activity assay kits were purchased from Nanjing KeyGen Biotech Co., Ltd. (Nanjing, China). Glutathione (GSH; cat. no. CEA294Ge) was purchased from Uscn Life Sciences, Inc. (Wuhan, China). Radioimmunoprecipitation assay (RIPA) lysis buffer and an Enhanced Chemiluminescence substrate kit were purchased from the Biomiga (San Diego, CA, USA) and Beyotime Institute of Biotechnology (Jiangsu, China), respectively. The bicinchoninic acid (BCA) protein assay kit was purchased from Bioteke Corporation (Beijing, China). Fas cell surface death receptor (Fas; dilution 1:4,000; cat. no. ab133619), B-cell lymphoma 2 (Bcl-2; dilution 1:4,000; cat. no. ab182858), Bcl-2 X-associated protein (Bax; dilution, 1:4,000; cat. no. ab32503), cytochrome $c$ (cyt c; dilution, 1:4,000; cat. no. ab76237) and $\beta$-actin (dilution, 1:4,000; cat. no. ab16039) primary antibodies were purchased from Abcam (Cambridge, England). A horseradish peroxidase (HRP)-conjugated goat anti-rabbit IgG secondary antibody (dilution 1:80,000; cat. no. IH-0011) was obtained from Wuhan Boster Biological Technology, Ltd. (Wuhan, China). All other chemicals were obtained from Nanjing Jiancheng Bio Institute (Nanjing, China).

POA was provided by the South China Sea Institute of Oceanology (Guangzhou, China). The structure of POA was elucidated by infrared (IR), nuclear magnetic resonance and mass spectrometry (MS) analyses, and its $>98 \%$ purity was determined by high performance liquid chromatography (HPLC) (8). POA was dissolved in DMSO and during the experiments, the DMSO content in the medium never exceeded $0.5 \%(\mathrm{v} / \mathrm{v})$.

Cell culture. L-02 cells were derived from healthy adult human livers and obtained from the Guangzhou Jennio Biotech Co., Ltd. (Guangzhou, China). Cells were maintained in RPMI 1640 media supplemented with $10 \%$ heat-inactivated FBS at $37^{\circ} \mathrm{C}$ in $5 \% \mathrm{CO}_{2}$. The cells were cultured for 3 days and culture medium was changed every 2 days. Cells for assay were detached by a solution of $0.25 \%$ trypsin and $0.02 \%$ EDTA.

Assessment of cell viability. L-02 cells ( $1 \times 10^{4}$ cells/well) were seeded into 96-well microplates and exposed to various

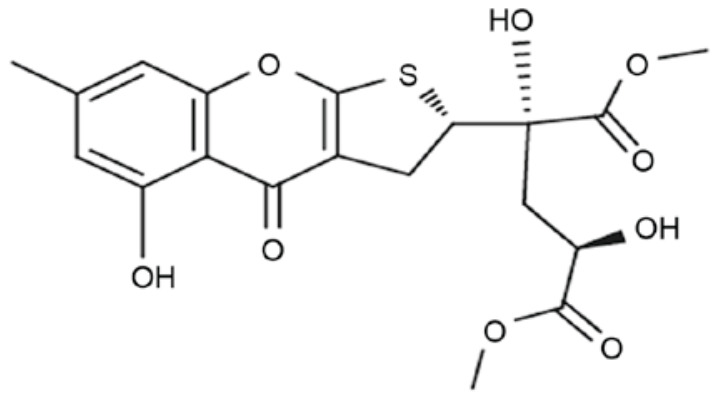

Figure 1. Chemical structure of oxalicumone A.

concentrations of POA $(10,20,30,40,50,60,70,80,90$ or $100 \mu \mathrm{M})$ for 24,48 or $72 \mathrm{~h}$. Cells treated without POA $(0 \mu \mathrm{M})$ served as a control in each experiment throughout the study. Subsequently, cells were incubated with $10 \mu \mathrm{l} \mathrm{CCK}-8$ for $2 \mathrm{~h}$, which provided effective and reproducible determination of the proliferative activity of L-02, as the dehydrogenases in surviving cells can convert CCK-8 to a colored formazan product. Finally, the optical density was measured at a wavelength of $450 \mathrm{~nm}$ using a microplate reader (PerkinElmer, Inc., Waltham, MA, USA) with a reference wavelength of $650 \mathrm{~nm}$. Three independent experiments were conducted in triplicate.

Assessment of morphological changes in the cell and nucleus. The morphologies of the L-02 cells after exposure to 20 or $40 \mu \mathrm{M}$ POA for $24 \mathrm{~h}$ were evaluated under a phase contrast optical microscope (Leica Microsystems $\mathrm{GmbH}$, Wetzlar, Germany). The morphological changes in the L-02 cells induced by POA were examined by fluorescent visualization under a fluorescence microscope (Leica, Microsystems $\mathrm{GmbH})$. Briefly, cells were treated similarly as described above, then washed twice with PBS, fixed with $4 \%$ paraformaldehyde for $10 \mathrm{~min}$ and incubated with Hoechst 33258 fluorescent dye $(5 \mathrm{mg} / \mathrm{ml})$ for $5 \mathrm{~min}$. Following this, cells were washed with PBS, dried, observed and imaged under a fluorescence microscope.

Assessment of apoptosis by the Annexin V/PI staining assay. POA-induced apoptosis was measured by Annexin V-FITC/PI double staining using a FACSCalibur flow cytometer (BD Biosciences, San Jose, CA, USA). In brief, subsequent to either sham $(0 \mu \mathrm{M})$ or POA exposure $(10,20$ or $40 \mu \mathrm{M})$ for 6 h, L-02 cells were harvested and washed twice with pre-cooled PBS, and resuspended with $500 \mu \mathrm{l}$ binding buffer, $5 \mu \mathrm{l}$ Annexin V-FITC conjugate and $5 \mu \mathrm{l}$ PI buffer, according to manufacturer's protocol. Cells were incubated in the dark for $15 \mathrm{~min}$ at room temperature, following which they were analyzed by flow cytometry, with each determination based on the acquisition of 10,000 events. The percentage of early apoptotic cells was calculated with the ratio of the total L-02 cell number.

For PI staining, cells were treated as described above, collected and centrifuged $\left(800 \times \mathrm{g}\right.$ for $5 \mathrm{~min}$ at $\left.4^{\circ} \mathrm{C}\right)$, washed twice with ice-cold PBS, then fixed in $70 \%$ chilled ethanol for $12 \mathrm{~h}$. After fixation, L-02 cells were washed and incubated in PBS containing $50 \mathrm{mg} / \mathrm{ml} \mathrm{PI,} 1 \mathrm{mg} / \mathrm{ml}$ RNase A and Triton X-100 (0.5\%) at $4^{\circ} \mathrm{C}$ for $30 \mathrm{~min}$ in the dark according to the instructions provided by the cell-cycle kit. Finally, 
the cells were assessed using a FACScan flow cytometer, and the percentage of nuclei with sub-G1 content was considered as apoptotic cells. The results were counted by a blind observer.

Activity of caspase 3 . The activity of caspase 3 was measured by a caspase 3 activity assay kit. In brief, the cells were treated either sham or POA $(10,20$ or $40 \mu \mathrm{M})$ for $24 \mathrm{~h}$, following which cells were harvested, washed twice with ice-cold PBS and resuspended in cold lysis buffer for $60 \mathrm{~min}$ at $4^{\circ} \mathrm{C}$. The lysate was centrifuged $\left(12,000 \mathrm{x} \mathrm{g}, 4^{\circ} \mathrm{C}, 5 \mathrm{~min}\right)$ and the supernatant was incubated with the enzyme specific colorimetric substrate Ac-DEVD-pNA in assay buffer for $2 \mathrm{~h}$ at $37^{\circ} \mathrm{C}$. The colorimetric release of pNA from the Ac-DEVD-pNA substrate was examined using a microplate reader (PerkinElmer, Inc.) with the optical absorbance at $405 \mathrm{~nm}$.

Protein expression levels of Fas, Bax and Bcl-2. The cytosolic fractions of Fas, Bax and Bcl-2 were extracted from the cell with RIPA lysis buffer containing $1 \%$ phenylmethanesulfonyl fluoride (PMSF), and the expression levels were detected by western blotting. Briefly, subsequent to either sham or POA exposure ( 20 or $40 \mu \mathrm{M}$ for $24 \mathrm{~h}$ ), $5 \times 10^{6}$ cells were trypsinized and harvested, then the treated cells were lysed in precooled lysis buffer and incubated on ice for $30 \mathrm{~min}$. The homogenate was centrifuged at $8,000 \mathrm{x} \mathrm{g}$ for $8 \mathrm{~min}$ at $4^{\circ} \mathrm{C}$, and the supernatant was transferred to an ice-cold $1.5 \mathrm{ml}$ tube and stored at $-20^{\circ} \mathrm{C}$ until further use. The concentration of total protein in the supernatant was determined by the BCA protein assay kit. Proteins (60 $\mu \mathrm{g} /$ lane) were separated by 12\% SDS-PAGE for $90 \mathrm{~min}$, and then were electrotransferred to a polyvinylidene difluoride membrane. Membranes were subsequently incubated with Fas, Bax and Bcl-2 primary antibodies, followed by incubation with corresponding HRP-conjugated secondary antibodies. Fas, Bax and Bcl-2 expressions were then detected using an ECL kit (Beyotime Institute of Biotechnology, Jiangsu, China) and analyzed by Gel.Doc2000 Gel imager (Bio-Rad Laboratories, Inc., Hercules, CA, USA) with Image Lab Software version 3.0 (Bio-Rad Laboratories, Inc.).

Assessment of oxidation state. To detect intracellular oxidation state, L-02 cells were treated as described above, but in 6 -well plates. Subsequently, the harvested cell suspension was washed with PBS ( $\mathrm{pH} 7.4)$, sonicated $(20 \mathrm{sec})$ in ice, and then centrifuged at $5,000 \mathrm{xg}$ for $10 \mathrm{~min}$ at $4^{\circ} \mathrm{C}$. The supernatant was transferred to fresh tubes and used for the enzymatic assays.

GSH content. The antioxidant enzyme GSH was measured by a GSH ELISA kit. The samples were prepared similarly as described above, according to the manufacturer's protocol. The assay is based on the depth of yellow, which is inversely associated with the content of GSH. The content of GSH was determined by measuring the optical absorbance at a wavelength $450 \mathrm{~nm}$ using a microplate reader (PerkinElmer, Inc.) Activity of GSH is expressed as $\mu \mathrm{g} / \mathrm{ml}$ protein.

Superoxide dismutase (SOD) activity. The activity of SOD was measured by the reduction of the formation of reddish violet crystals using a microplate reader at a wavelength of $550 \mathrm{~nm}$, then the precise result was obtained through the formula calculation of the manufacturer's protocol based on cellular protein concentration. Protein concentrations were determined by using a formula calculation based on absorbance values at $550 \mathrm{~nm}$ (10). Activity of SOD is expressed as U/mg protein.

Determination of lipid peroxidation. The content of malondialdehyde (MDA) was measured by a MDA detection kit (Nanjing Jiancheng Bio Institute) according to the manufacturer's protocol. MDA reacts with thiobarbituric acid (TBA) at $95-100^{\circ} \mathrm{C}$ in acidic conditions and produces a pink colored MDA-TBA conjugate, which has an absorbance at a wavelength of $532 \mathrm{~nm}$ using a microplate reader. MDA was calculated based on cellular protein concentration. Cellular MDA is expressed $\mathrm{nmol} / \mathrm{mg}$ cellular protein.

Assessment of nitric oxide (NO). The content of NO was measured by a NO detection kit (Nanjing Jiancheng Bio Institute), which conducted following the manufacturer's protocol. NO reacts with oxygen and water is converted into nitrate and nitrite, which can change to a pink azo compound in a nitrate chromogenic agent. NO levels were determined by measuring the optical density of colored formation at $550 \mathrm{~nm}$ with a microplate reader. NO content was calculated based on cellular protein concentration, with sodium nitrite to generate the standard curve. Cellular NO content is expressed $\mu \mathrm{mol} / \mathrm{g}$ cellular protein.

Measurement of alanine aminotransferase (ALT) and aspartate aminotransferase (AST). The levels of ALT and AST were calculated using ALT and AST detection kits (Nanjing Jiancheng Bio Institute), according to the manufacturers' protocol. The absorbance was measured at a wavelength of $510 \mathrm{~nm}$ with a microplate reader. Cellular ALT and AST contents are expressed U/mg cellular protein with pyruvic acid sodium to generate the standard curve.

Lactate dehydrogenase ( $L D H)$ leakage assay. The LDH leakage assay was assessed by a LDH cytotoxicity detection ELISA kit (cat. no. CSB-E11720h; CUSABIO Biotech. Co., Ltd., Wuhan, China) according to the manufacturer's protocol. The concentration of LDH was determined by measuring the optical density at $450 \mathrm{~nm}$ with a microplate reader according to the standard curve, and the calculation was based on cellular protein concentration.

Measurement of reactive oxygen species (ROS) production. ROS accumulation in cells was measured by a ROS detection kit (Nanjing Jiancheng Bio Institute) using the cell permeable fluorescent dye 2,7-dichlorofluorescin diacetate (DCFH-DA). The intracellular esterases hydrolyze DCFH-DA to DCFH, which is oxidized to DCF by the oxidants; its fluorescence is a measure of ROS production in the cell. A BD flow cytometer with BD CFlow software v.264.15 (BD Biosciences) was used to measure the fluorescence intensity at excitation and emission wavelengths of 485 and $530 \mathrm{~nm}$, respectively.

Assessment of mitochondrial membrane potential (MMP). To monitor the loss of MMP, L- 02 cells $\left(5 \times 10^{5}\right.$ cells $\left./ \mathrm{ml}\right)$ in 6 -well culture plates were treated without or with $\mathrm{POA}(10,20$ or $40 \mu \mathrm{M})$ for $24 \mathrm{~h}$. Reaction medium ( $\mathrm{pH} 7.4$ ) containing $5 \mu \mathrm{g} / \mathrm{ml} \mathrm{JC}-1$ 
cationic dye were preincubated at $37^{\circ} \mathrm{C}$. Cells were trypsinized and harvested, washed twice with ice-cold PBS, then incubated with reaction medium for $30 \mathrm{~min}$ in darkness at $37^{\circ} \mathrm{C}$. Finally, cells were washed twice with PBS then analyzed by flow cytometry as described above, within $1 \mathrm{~h}$.

Assessment of adenosine triphosphate (ATP). The ATP level was determined using an ATP detection kit (Nanjing Jiancheng Bio Institute) according to the manufacturer's protocol. In brief, L-02 cells were treated without or with POA (10, 20 or $40 \mu \mathrm{M})$ for $24 \mathrm{~h}$, then cells were harvested and centrifuged $\left(2,400 \times \mathrm{g}, 5 \mathrm{~min}, 4^{\circ} \mathrm{C}\right)$, and the cell pellet was ultrasonicated for $5 \mathrm{sec}$. The optical density was detected at a wavelength of $660 \mathrm{~nm}$ with a microplate reader and the concentration was calculated according to the standard curve, based on cellular protein concentration. Cellular ATP content is expressed as $\mathrm{U} / \mathrm{mg}$ cellular protein.

Assessment of mitochondrial permeability transition pore (MPTP). The MPTP was determined with a MPTP kit (Nanjing Jiancheng Bio Institute) according to the manufacturer's protocol. Mitochondrial relative fluorescence intensity as an indicator of MPTP was estimated from the decrease using an excitation wavelength of $480 \mathrm{~nm}$ and an emission wavelength of $530 \mathrm{~nm}$. Data are reported as fold in fluorescence intensity relative to the control.

Assessment of the release of cyt $c$ from mitochondria. The cytosolic fraction of cyt $\mathrm{c}$ was extracted from the cell with RIPA lysis buffer containing 1\% PMSF and detected by western blotting. Briefly, L-02 cells were treated without or with POA ( 20 or $40 \mu \mathrm{M}$ for $24 \mathrm{~h}$ ), 5x10 $0^{6}$ cells were trypsinized and harvested, and the treated cells were lysed in precooled lysis buffer on ice for $30 \mathrm{~min}$. The homogenate was centrifuged at $8,000 \mathrm{xg}$ for $8 \mathrm{~min}$ at $4^{\circ} \mathrm{C}$, and the supernatant was transferred to an ice-cold $1.5 \mathrm{ml}$ tube and stored at $-20^{\circ} \mathrm{C}$ until further use. The protein concentration in the supernatant was determined by the BCA protein assay kit. Equal amounts of protein $(60 \mu \mathrm{g} / \mathrm{lane})$ were separated by $12 \%$ SDS-PAGE and were electrotransferred to a polyvinylidene difluoride membrane. The membrane was then incubated in 5\% non-fat milk in TBS with Tween-20 (TBST) for $2 \mathrm{~h}$ followed by overnight incubation with the cytochrome $c$ antibody at $4^{\circ} \mathrm{C}$. The incubated membrane was washed with TBST before incubation for $1 \mathrm{~h}$ with a HRP-conjugated goat anti-rabbit IgG secondary antibody at $25^{\circ} \mathrm{C}$. Membranes were washed with TBST, and proteins were detected by an ECL kit (Beyotime Institute of Biotechnology, Jiangsu, China) and analyzed by Gel.Doc2000 Gel imager (Bio-Rad Laboratories, Inc.) with Image Lab Software version 3.0 (Bio-Rad Laboratories, Inc.).

Electron microscopy of mitochondria. The morphological changes of mitochondria were observed by electron microscopy assay. In brief, L- 02 cells were exposed to POA $(0,10,20$ or $40 \mu \mathrm{M}$ for $24 \mathrm{~h}$ ), then trypsinized and harvested for transmission electron microscopy. Cells samples of a maximum size of $1 \mathrm{~mm}^{3}$ were collected and prefixed in PBS (pH 7.2) supplemented with $2.5 \%$ glutaraldehyde for $4 \mathrm{~h}$, according to a method described previously (11). Finally, the sections were observed under a transmission electron microscope.

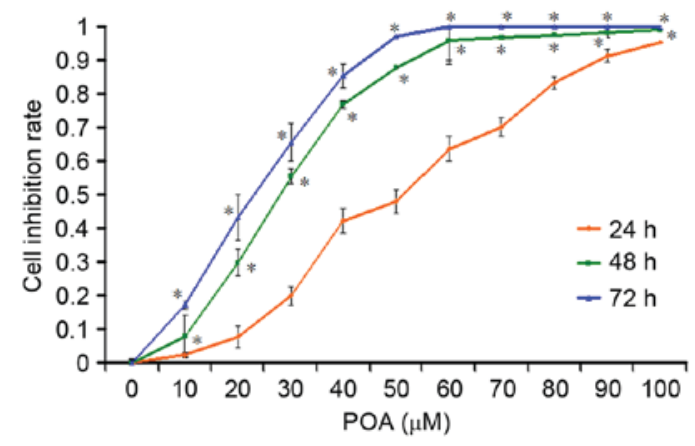

Figure 2. Concentration- and time-dependent inhibition effect of POA in L-02 cells. L-02 cells were treated with $0,10,20,30,40,50,60,70,80,90$ or $100 \mu \mathrm{M}$ POA for 24,48 or $72 \mathrm{~h}$. Data are presented as the mean \pm standard deviation from three independent experiments. ${ }^{*} \mathrm{P}<0.01 \mathrm{vs} .24 \mathrm{~h}$ at each concentration. POA, oxalicumone A.
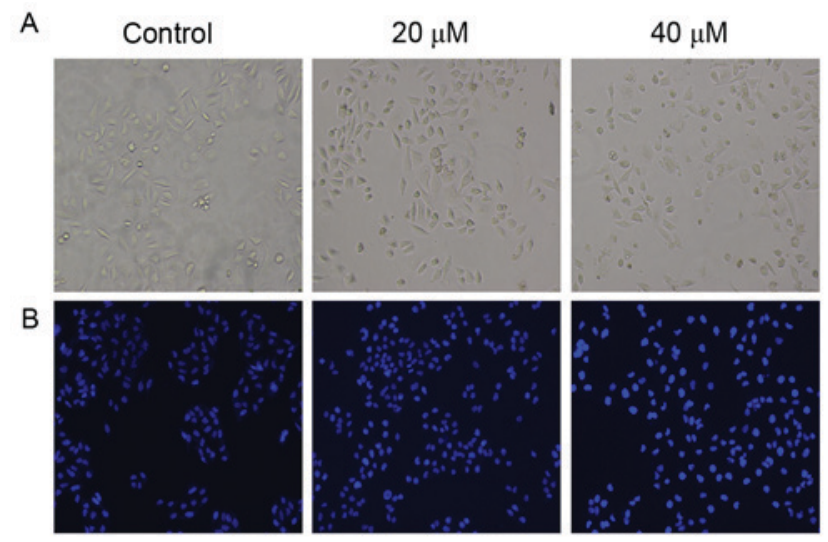

Figure 3. Morphological changes in L-02 cells and nuclei in response to oxalicumone A treatment for $24 \mathrm{~h}$. (A) Phase contrast images of L-02 cells following various treatments (magnification, x100). (B) Fluorescence photomicrograph of L-02 cells stained with Hoechst 33258 following various treatments (magnification, x100).

Statistical analysis. Values are presented as the mean \pm standard deviation of at least three independent experiments. Statistical differences were analyzed by one way analysis of using SPSS version 17.0 software (SPSS, Inc., Chicago, IL, USA). Student's $\mathrm{t}$-test was used for comparison between two groups. $\mathrm{P}<0.05$ was considered to indicate a statistically significant difference.

\section{Results}

Cytotoxicity induced by POA in L-02 cells. The cytotoxicity of POA in L-02 cells was determined using the CCK-8 assay, which is a sensitive, quantitative and reliable method to analyze cell viability and cell growth. The cell growth inhibition after treatments with various concentrations of POA for 24,48 or $72 \mathrm{~h}$ is presented in Fig. 2. As expected, in comparison with the control cells, POA significantly decreased L-02 cell viability in a typical dose- and time-dependent manner $(\mathrm{P}<0.01$ vs. control). DMSO alone did not show any inhibitory effect on the cell viability.

Morphological changes induced by POA in L-O2 cells. As presented in Fig. 3A, in the absence of POA, L-02 cells had a common spindle shape, whereas POA treatment (20 and $40 \mu \mathrm{M})$ 
A

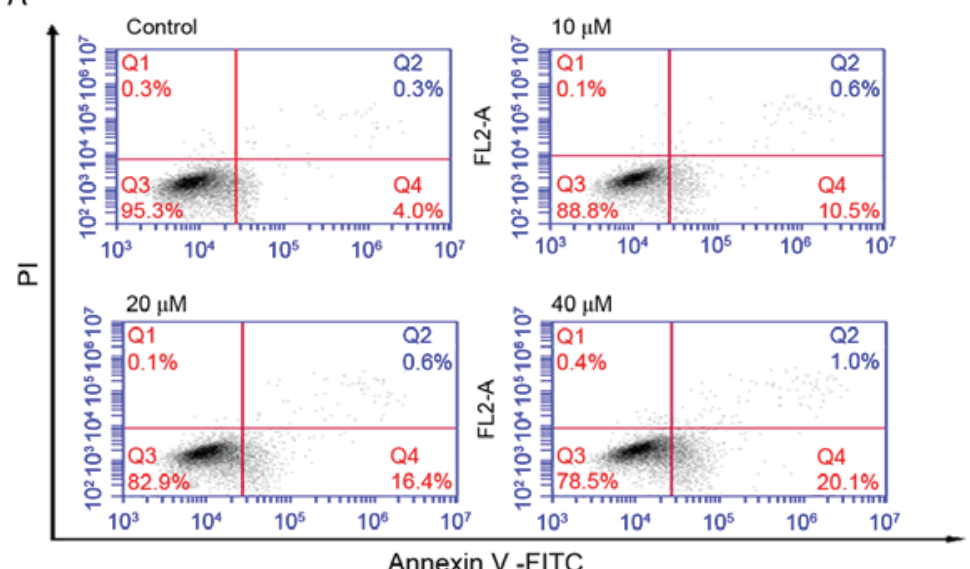

B

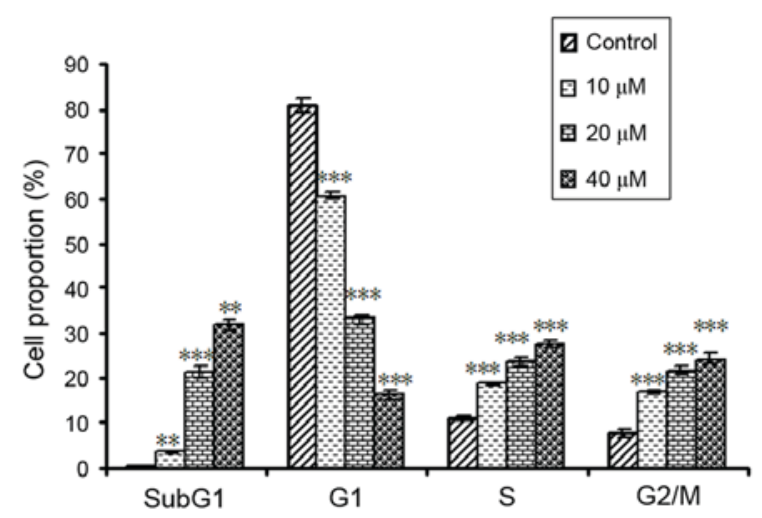

C

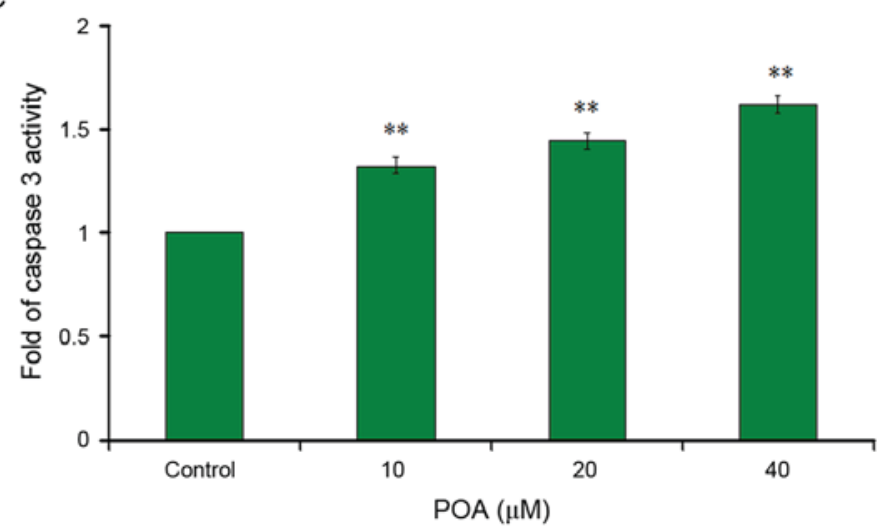

Figure 4. (A) The percentage of apoptotic cells analyzed by flow cytometric analysis of Annexin V FITC/PI double staining. (B) The percentage of cell cycle phase was analyzed by flow cytometry analysis. (C) Activity of caspase 3 in L-02 cells after treatment with or without (control) POA. Data are presented as the mean \pm standard deviation from three independent experiments. ${ }^{* *} \mathrm{P}<0.01,{ }^{* * * *} \mathrm{P}<0.001$. FITC, fluorescein isothiocyanate; PI, propidium iodide; POA, oxalicumone A.

resulted in increased shrinkage and detachment from the substrate as the exposure dose increased (Fig. 3A). After the treatments, the L-02 cells were stained with Hoechst 33258 and visualized to investigate the incidence of apoptosis. As presented in Fig. 3B, in the absence of POA, the L-02 cells had almost uniform Hoechst 33258 (blue) staining with intact nuclei, and appeared to proliferate in spindle-like shapes in the wells. While in the presence of POA $(20$ and $40 \mu \mathrm{M})$, the apoptotic cells were characterized by brighter blue with nuclear condensation and chromatin margination in a dose-dependent manner, indicating an increased apoptosis in these cells (Fig. 3B).

Effects of POA on early apoptosis and cell cycle in L-O2 cells. As presented in Fig. 4A, when L-02 cells were treated with $0,10,20$ or $40 \mu \mathrm{M}$ POA for $6 \mathrm{~h}$, significant increases in the percentage of early apoptotic cells (Annexin $\mathrm{V}^{+} / \mathrm{PI}^{-}$staining) were observed, with increases from $4.0 \%$ at $0 \mu \mathrm{M}$, to $10.5 \%$ at $10 \mu \mathrm{M}, 16.4 \%$ at $20 \mu \mathrm{M}$ and $20.1 \%$ at $40 \mu \mathrm{M}$. The inhibitory effect of POA on L-02 cell growth was further investigated using flow cytometric analysis. The amounts of apoptotic cells were determined by the sub-G1 apoptotic peaks, which may be attributed to their lower cellular DNA content in case of DNA crazing. Apoptotic peaks and the distributions of the cells in various phases of the cell cycle were observed after 24 h treatment with POA $(10,20$ and $40 \mu \mathrm{M})$. As presented in Fig. 4B, POA induced an increase in sub-G1 apoptotic peaks and $\mathrm{S}$-phase cell populations in a dose-dependent manner, indicating an accelerated cell cycle. The result was accompanied by a marked increase of the percentage of cells in the $\mathrm{G} 2 / \mathrm{M}$ phase, while the percentage of cells in the G1 phase exhibited a significant reduction. The results of Annexin V-PI double-labeling assay and cell-cycle analysis indicated that growth inhibition was accompanied with an increase in apoptotic cells in a dose-dependent manner.

Effect of POA on caspase 3 activity in L-O2 cells. Caspase 3 mainly exists in the cytoplasm in normal state; during apoptosis, it is energized into two large and two small subunit compositions, which can break the cytoplasm and nucleus, eventually leading to apoptosis. As presented in Fig. 4C, when L-02 cells were exposed to POA $(10,20$ and $40 \mu \mathrm{M})$ for $24 \mathrm{~h}$, the activities of caspase 3 were significantly increased $(\mathrm{P}<0.01)$ in a concentration-dependent manner, compared with cells treated without POA.

Effect of POA on levels of apoptotic proteins in L-02 cells. As presented in Fig. 5A and B, POA $(0,20$ or $40 \mu \mathrm{M})$ treatment for $24 \mathrm{~h}$ increased the protein expression of Fas compared with the control $(0 \mu \mathrm{M})$. Additionally, the protein expression of $\mathrm{Bcl}-2$ decreased with exposure to POA at increasing concentrations 
A

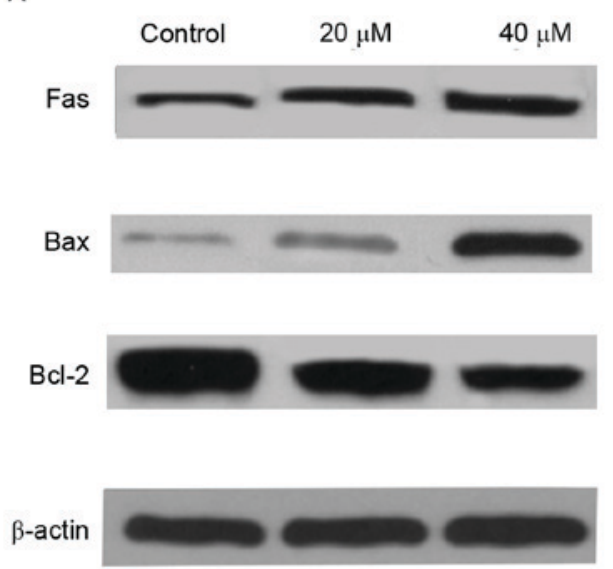

B

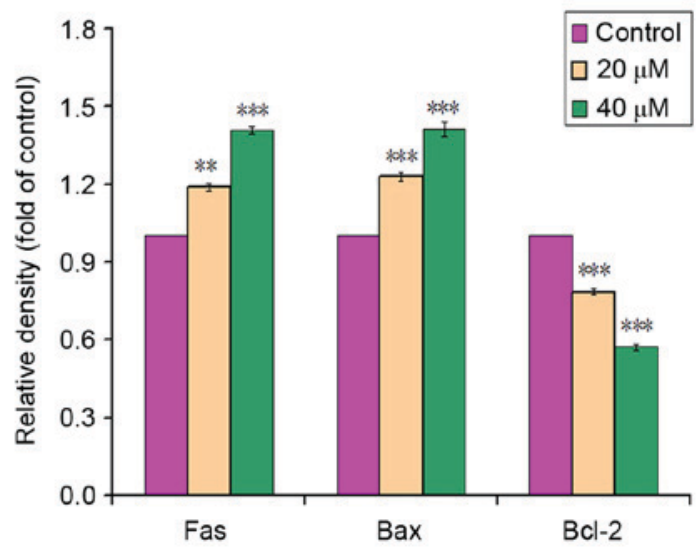

Figure 5. Effect of oxalicumone A on protein expression levels of Fas, Bax and Bcl-2 in L-02 cells. $\beta$-actin served as internal control. (A) Representative western blot images and (B) quantification from at least three experiments. Data are presented as the mean \pm standard deviation. ${ }^{* *} \mathrm{P}<0.01,{ }^{* * *} \mathrm{P}<0.001$. Fas, Fas ligand; Bax, B-cell lymphoma 2 X-associated protein; Bcl-2, B-cell lymphoma 2.

$(0,20$ and $40 \mu \mathrm{M})$, while that of Bax increased in POA-treated cells in comparison with control cells. The results of the expression levels of apoptotic proteins indicated that POA may upregulate the expression levels of Fas and Bax, and downregulate Bcl-2 expression, in a concentration-dependent manner.

Effects of POA on oxidative stress. GSH is a ubiquitous sulfhydryl-containing molecule in cells that is responsible for maintaining cellular oxidation-reduction homeostasis. Changes in GSH homeostasis can be monitored as an indication of cell damage. As presented in Fig. 6A, POA induced a decrease in the level of GSH. The levels of GSH were 0.932 -fold at $10 \mu \mathrm{M}$, 0.821 -fold at $20 \mu \mathrm{M}$ and 0.719 -fold at $40 \mu \mathrm{M}$ of control, respectively. Compared with the control $(44.03 \mathrm{U} / \mathrm{ml})$, POA markedly decreased SOD activity to $37.31 \mathrm{U} / \mathrm{ml}$ at $10 \mu \mathrm{M}, 32.73 \mathrm{U} / \mathrm{ml}$ at $20 \mu \mathrm{M}$ and $30.72 \mathrm{U} / \mathrm{ml}$ at $40 \mu \mathrm{M}$ (Fig. 6B). Additionally, POA induced a significant increase in the level of MDA from $0.57 \mathrm{nmol} / \mathrm{mg}$ at $0 \mu \mathrm{M}$ to $0.71 \mathrm{nmol} / \mathrm{mg}$ at $10 \mu \mathrm{M}$ and $0.79 \mathrm{nmol} / \mathrm{mg}$ at $20 \mu \mathrm{M}(\mathrm{P}<0.05 \mathrm{vs}$. control $)$ and $1.36 \mathrm{nmol} / \mathrm{mg}$ at $40 \mu \mathrm{M}(\mathrm{P}<0.001$ vs control; Fig. 4C). Furthermore, POA inhibited NO production in a dose-dependent manner, from $21.43 \mu \mathrm{mol} / 1$ in control cells to $13.41,8.94$ and $3.14 \mu \mathrm{mol} / 1$ after 10, 20 and $40 \mu \mathrm{M}$ POA, respectively (Fig. 4D).

The results indicated that POA increased the activities of ALT (Fig. 6E) and AST (Fig. 6F) in a dose-dependent manner. The ALT level was increased to $2.38,3.99,5.87 \mathrm{U} / \mathrm{g}$ protein compared with the control (0.65 U/g protein), and AST levels were increased to $2.75,6.25,8.43$ compared with the control (1.75 U/g protein) in cells treated with 10,20 and $40 \mu \mathrm{M}$ for $24 \mathrm{~h}$, respectively.

Membrane damage that leads to LDH leakage is generally considered irreversible. Thus, LDH leakage was applied to as a biomarker for cellular viability. As presented in Fig. 6G, LDH leakage was identified in POA-induced L-02 cells in a dose dependent manner: 1.48 -fold at $10 \mu \mathrm{M}, 2.08$-fold at $20 \mu \mathrm{M}$ and 3.06-fold at $40 \mu \mathrm{M}$ compared with control cells.

Effect of POA on ROS production in L-O2 cells. DCFH-DA is generally used to measure ROS generation in cells. As presented in Fig. 7, ROS production following a 24-h exposure to POA increased in a concentration-dependent manner. The level of ROS in L-02 cells increased from $4.2 \%$ at $0 \mu \mathrm{M}$ to $14.2 \%$ at $10 \mu \mathrm{M}, 19.5 \%$ at $20 \mu \mathrm{M}$ and $23.1 \%$ at $40 \mu \mathrm{M}$.

Effects of POA on mitochondrial function in L-02 cells. MMP was determined by the uptake of JC-1 (a molecular probe) using flow cytometric assay. As presented in Fig. 8A, MMP depolarization following a 24-h exposure to POA (10, 20 and $40 \mu \mathrm{M})$ significantly increased in a dose-dependent manner. The percentage of depolarized cells were 14.2, 19.5 and $23.1 \%$ in the samples treated with 10,20 and $40 \mu \mathrm{M}$, respectively, while the value in control cells was $4.2 \%$. Therefore, POA-induced mitochondrial damage resulted in disruption of MMP.

Concentrations of ATP in L-02 cells treated with POA are presented in Fig. 8B. The ATP level decreased from $1.85 \mathrm{U} / \mathrm{mg}$ at $0 \mu \mathrm{M}$ to $1.39 \mathrm{U} / \mathrm{mg}$ at $10 \mu \mathrm{M}, 0.81 \mathrm{U} / \mathrm{mg}$ at $20 \mu \mathrm{M}$ and $0.50 \mathrm{U} / \mathrm{mg}$ at $40 \mu \mathrm{M}$, which indicated that POA induced the decrease of ATP in a dose-dependent manner.

The results of the MPTP assay are presented in Fig. 8C. The relative fluorescence intensity decreased compared with the control in a dose-dependent manner, and was 0.78 at $10 \mu \mathrm{M}, 0.60$ at $20 \mu \mathrm{M}$ and 0.41 at $40 \mu \mathrm{M}$. This suggested an increasing number of cells with mitochondrial membrane depolarization or breakdown.

Effects of POA on cyt c. As presented in Fig. 9, POA treatment significantly increased the protein expression levels of cyt $c$ compared with control cells $(\mathrm{P}<0.001$ vs. control), which in parallel with mitochondrial membrane breakdown, indicated that POA increases the release of the cyt $c$ protein from the mitochondria into the cytosol.

Electron microscopy findings. A transmission electron microscope was used to observe the cell mitochondrial internal structure. In L-02 cells there were lesions in the mitochondria of POA treated cells compared to sham treated cells. In the blank control group, mitochondrial structures had a regular shape, were distributed in cells regularly and mitochondrial crests were arranged by rule (Fig. 10A), whereas cells treated 


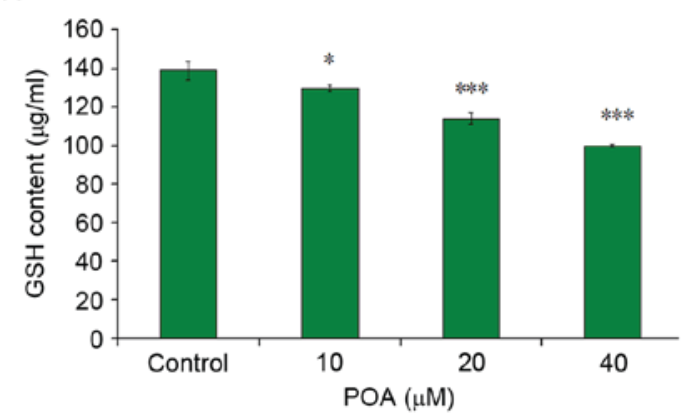

C

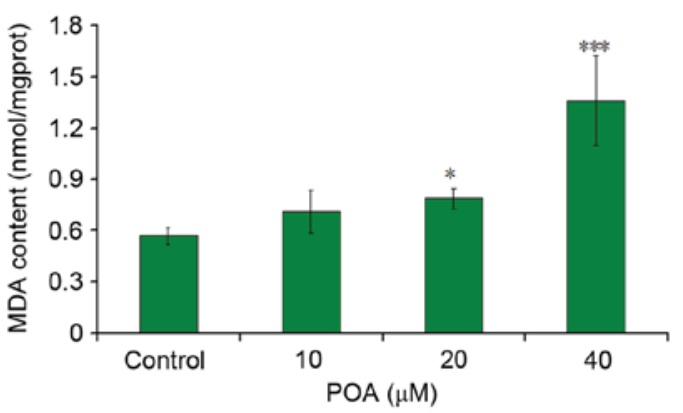

E

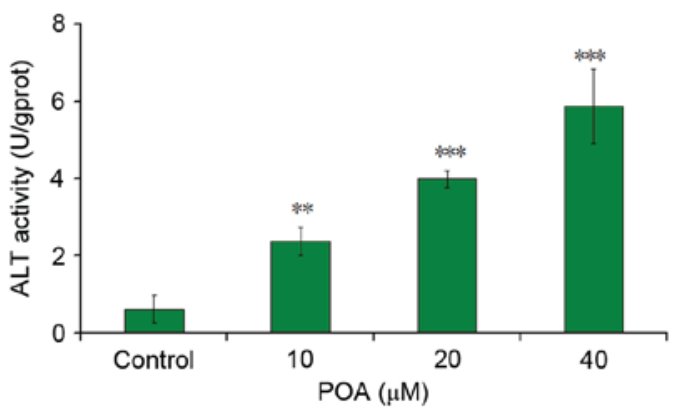

B

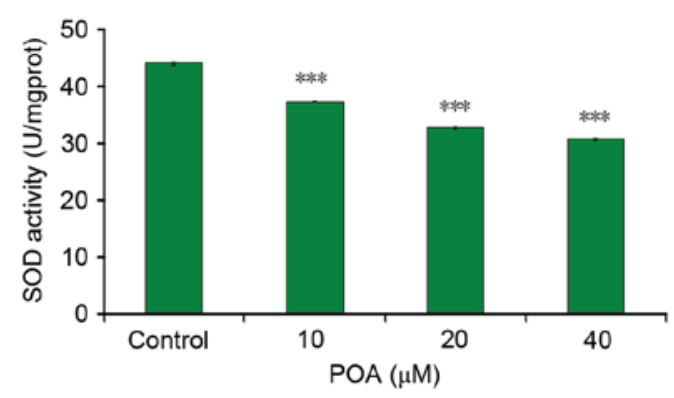

D

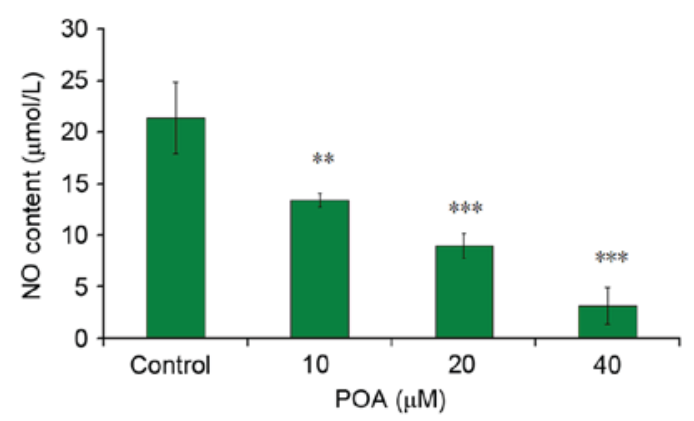

$\mathrm{F}$

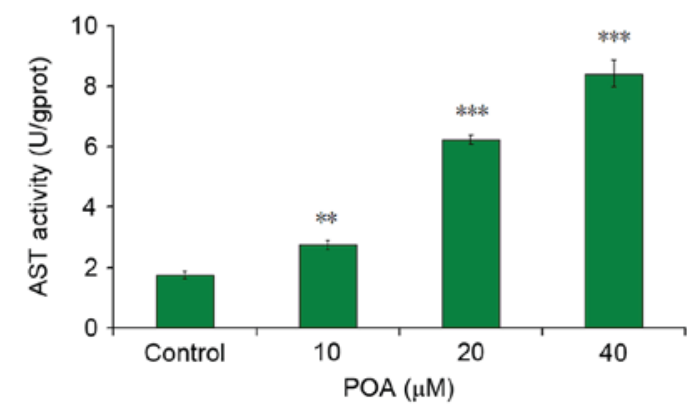

G

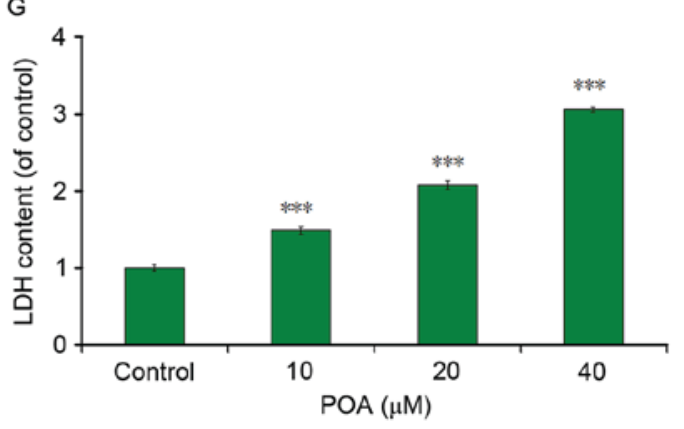

Figure 6. Effect of POA on (A) GSH activity, (B) SOD activity, (C) MDA formation, (D) NO content, (E) ALT content, (F) AST content and (G) LDH content in L-02 cells. Data are presented as the mean \pm standard deviation. ${ }^{*} \mathrm{P}<0.05,{ }^{* *} \mathrm{P}<0.01,{ }^{* * * *} \mathrm{P}<0.001$. GSH, glutathione; MDA, malondialdehyde; NO, nitric oxide; ALT, alanine aminotransferase; AST, aspartate aminotransferase; LDH, lactate dehydrogenase; SOD, superoxide dismutase; POA, oxalicumone A.

with 10 (Fig. 10B), 20 (Fig. 10C) and $40 \mu \mathrm{M}$ (Fig. 10D) POA exhibited increased vacuole sizes, mitochondrial swelling and disappearance of mitochondrial matrix particles. Furthermore, the areas of vacuoles increased to more than half than that of the mitochondria, and integrated mitochondria around the nucleus were rare as the dose increased.

\section{Discussion}

POA was isolated from a culture broth of the South China Sea fungus Penicillium oxalicum SCSGAF0023 (8). Although POA has previously been indicated to induce cytotoxicity in human carcinoma (12), to the best of our knowledge, there have not been previous studies on the cytotoxicity of POA on L-02 cells human normal liver cells, which has been a major limitation in the clinical application of POA. The present study investigated POA-induced cytotoxicity and its toxic mechanisms in L-02 cells. It was demonstrated that the toxicological mechanisms of POA on human normal liver cells mainly included oxidative stress injury and mitochondrial dysfunction.

In the CCK- 8 assay of cell viability, POA inhibited the proliferation of L-02 cells in a concentration- and time-dependent 

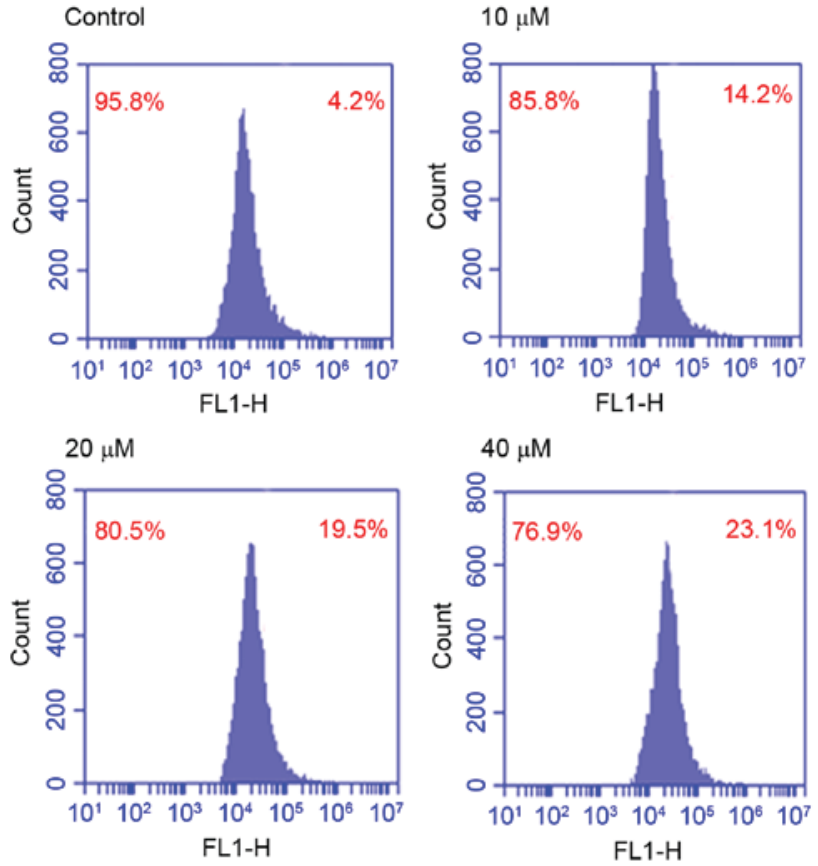

Figure 7. Effect of oxalicumone A on reactive oxygen species production in L-02 cells.

manner, which demonstrated that POA induced cytotoxicity in L-02 cells. POA inhibited L-02 cell proliferation, potentially via apoptosis-associated processes. Apoptosis, a highly structured and ordered process, eliminates superfluous, harmful and metabolically perturbed cells, and is a fundamental form of cell death (13). In the present study, apoptosis was induced by POA in L-02 cells, as evidenced by typical morphological changes in the cell and nucleus assayed by Hoechest 33258 staining, such as karyopyknosis, deepened stains and karyorrhexis, along with cellular shrinkage, chromatin condensation, nuclear fragmentation shrinkage and nuclear condensation or fragmentation. Furthermore, Annexin V/PI double staining and cell cycle arrest assays further confirmed apoptosis by flow cytometry; they demonstrated that POA markedly and progressively increased the percentage of early apoptosis of the cells as the concentration increased, compared with the control. Meanwhile, POA largely increased the sub-G1 cell population in a whole cell cycle, which is a hallmark of apoptosis (14), along with causing S-phase arrest. Additionally, POA was able to activate caspase 3 , which is a key executioner of apoptosis (15), thus providing a reasonable explanation for cytotoxic activities in L-02 cells induced by POA, directly demonstrating that the mechanism of cytotoxicity is associated with the apoptosis.

To elucidate the molecular toxic mechanism of the POA, the expression of apoptosis proteins were detected, including Fas, Bax and Bcl-2. It has previously been reported that the extrinsic apoptotic signaling pathway is initiated by binding of the Fas ligand to the ectodomain of the surface death receptor Fas protein, which triggers activation of caspases that induce cell death $(16,17)$. Thus, Fas serves an important role in the initiation of the cell death signaling pathway (18). The present study identified that POA promoted the expression of Fas protein, which further demonstrated that POA induced apoptosis in L-02 cells in accordance with the results described above, potentially via the intrinsic signaling apoptotic pathway.

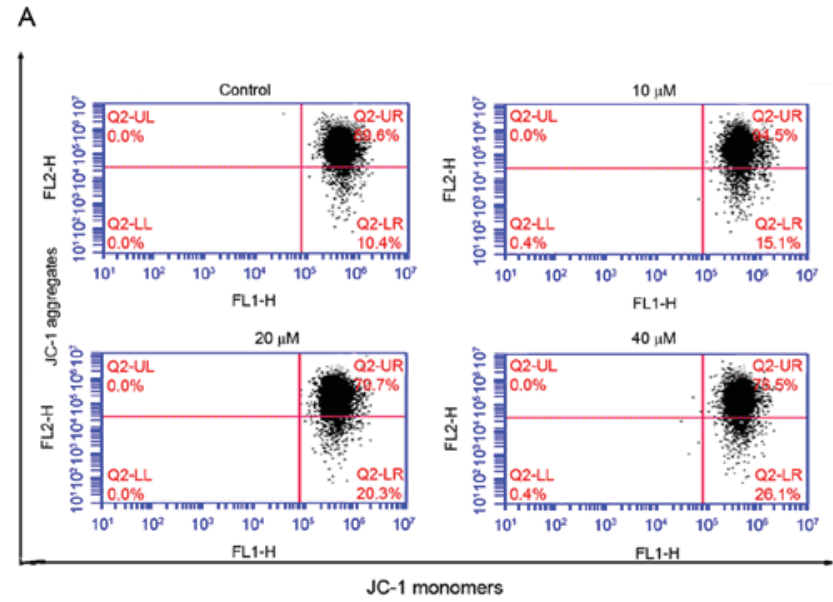

B

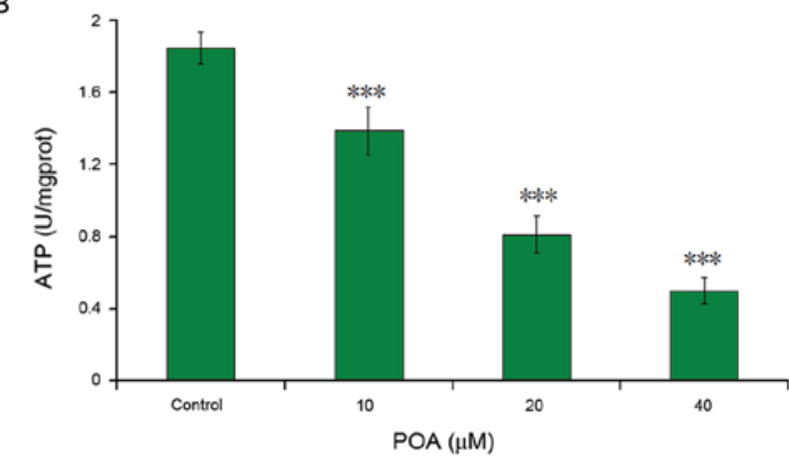

C

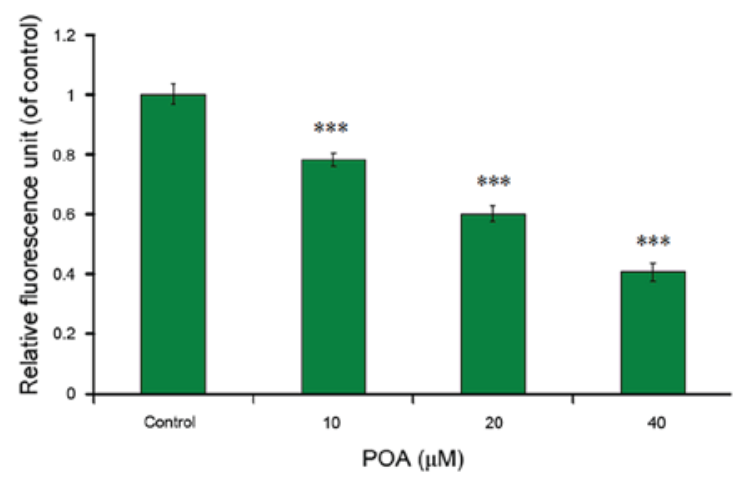

Figure 8. Effects of POA on (A) MMP, (B) ATP and (C) MPTP in L-02 cells. Data are presented as the mean \pm standard deviation. ${ }^{* * *} \mathrm{P}<0.001$. MMP, mitochondrial membrane potential; ATP, adenosine triphosphate; MPTP, mitochondrial permeability transition pore; POA, oxalicumone A; JC-1, 5,5,6,6-tetra-chloro-1,1,3,3-tetraethylbenzimidazolyl-carbocyanine iodide.

The Bcl-2 family, which serves a key role in deciding the fate of cells, can be divided into either anti-apoptotic or pro-apoptotic members (19). Apoptosis is also understood to be critically dependent on the balance between the Bax and the $\mathrm{Bcl}-2$ proteins $(20,21)$. Therefore, the expression levels of Bax and Bcl-2 were detected by western blotting. The results indicated that POA increased the expression of the pro-apoptotic protein $\mathrm{Bax}$ and decreased the expression of anti-apoptotic protein Bcl-2, suggesting that POA may alter the balance between anti- and pro-apoptotic protein members, ultimately inducing apoptosis in L-02 cells involving the Bcl-2 family protein.

Oxidative stress serves a role in the mechanisms of toxicity in a number of compounds, whether by production of free 
A

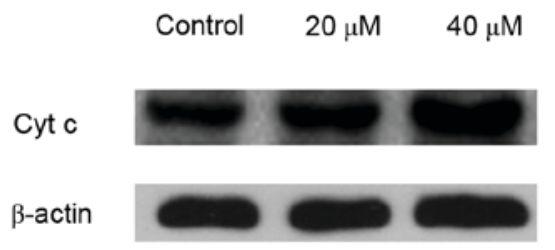

B

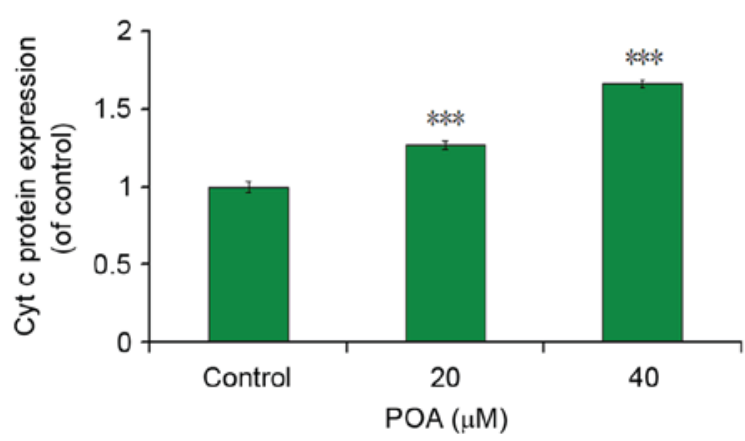

Figure 9. Effect of POA on expression levels of cyt $c$ in L-02 cells. $\beta$-actin served as an internal control. (A) Representative western blot images and (B) quantification from at least three experiments. Data are presented as the mean \pm standard deviation. ${ }^{* * * *} \mathrm{P}<0.001$. Cyt $c$, cytochrome $c$; POA, oxalicumone A.
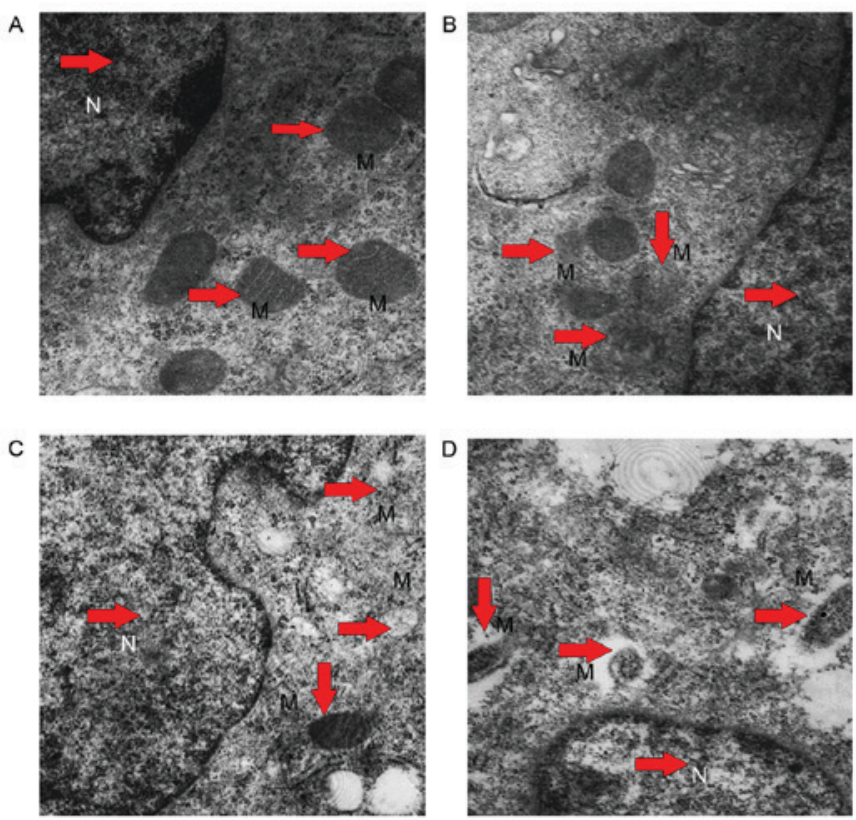

Figure 10. Effects of POA on mitochondria in L-02 cells, as assessed by transmission electron microscopy observation (magnification, $\mathrm{x} 10,000$ ) (A) Control; (B) $10 \mu \mathrm{M}$, (C) $20 \mu \mathrm{M}$ and (D) $40 \mu \mathrm{M}$ POA treatment. N, cell nucleus; $\mathrm{M}$, mitochondria; POA, oxalicumone A.

radicals or by depletion of cellular antioxidant capacity. Cellular integrity is affected by oxidative stress when the production of reactive oxidants overwhelms antioxidant defense mechanisms. The disruption of cellular redox balance by exogenous substances may lead to cell damage. GSH, non-enzymatic substance, is an omnipresent sulfhydryl-containing molecule in cells, which is responsible for maintaining cellular oxidation-reduction homeostasis and changes in the homeostasis that are as a sign of cell damage (22). SOD is a ubiquitous component of cellular antioxidant systems, which can convert superoxide anions to hydrogen peroxide and fight the damage resulting from the oxygen free radical to cells, rapidly repairing damaged cells. The present study demonstrated that POA reduced the content of GSH and the activity of SOD. These results indicated that the GSH and SOD antioxidant system is involved in POA-induced oxidative stress injury in L-02 cells. It has been reported that the promotion of MDA, which is the main end production of lipid peroxidation, is an indication of membrane lipid damage, as membrane lipids are major targets of free radicals (23). On the other hand, $\mathrm{NO}$ is a free radical, which takes part in many pathological processes; a small amount of NO serves a physiological role, whereas a large amount of NO induces cell damages. The present study revealed that POA elevated MDA and NO levels, which suggested that POA induced lipid peroxidation injury in L-02 cells, and the oxidative stress served an important role in POA-induced cytotoxicity.

ALT and AST mainly exist in liver cells, and translocate to the outer membrane from the interior once necrosis or liver damage occur. They are sensitive indicators for the examination of liver function in clinical treatment, and are used to assess the damage of liver cells. The present study demonstrated an increase in levels of ALT and AST in comparison with the control, which revealed that POA induced damage in L-02 cells. Similarly, LDH is a glycolytic enzyme that exists in the cytoplasm of cells; when cells are damaged, it leaks from the interior to the outer of cells. The LDH leakage test indicated that the amount of LDH in treatments was increased compared with the sham, which indicated that POA induced damage in L-02 cells, consistent with ALT and AST results.

ROS are by-products of biological redox reactions and are associated with various pathological conditions. They increase following exposure to harmful substances and rely on the balance between oxidative and antioxidant cellular system (24). In turn, excessive harmful substances can disturb this balance by creating increased formation of ROS through mitochondria dysfunction or diminishing and/or inhibiting antioxidant system, and the overproduction of ROS may induce apoptosis and cell death (25). The present study demonstrated that POA significantly increased ROS production in a dose-dependent manner, which is consistent with the above results of cytotoxicity and oxidative stress injury induced by POA in L-02 cells.

Mitochondria serve a key role in apoptosis, and the mitochondrial apoptotic pathway has been suggested as a pivotal signaling pathway of apoptosis (26). The most crucial effect of oxidant stress is the increased opening of the MPTP, resulting in the collapse of membrane potential and interruption of ATP synthesis (27). Certain drugs can lead swollen mitochondria, abnormal or cracked cristae and reduced matrix density in liver cells. The MMP formed by electrons within the mitochondrial respiratory chain couples with the extrusion of protons from 
the mitochondrial matrix to the intermembrane space, which is the driving force for phosphorylation of ADP in the process of oxidative phosphorylation (28). A previous study confirmed that the depolarization of MMP is an irreversible cause of early apoptosis (29). In the present study, incubation of activated mitochondria with POA resulted in an abrupt depletion of ATP synthesis, MPTP opening and mitochondria swelling, vacuolation, and reduced matrix density. Furthermore, POA induced the depletion of MMP; as it is reported that alternations in the mitochondrial functions via the increase of ROS generation and disruption of MMP may lead to cell death (30), these results indicated that POA induced damage in mitochondria, thus causing cytotoxicity in L- 02 cells. Furthermore, the exposure of L-02 cells to POA resulted in an abrupt release of cyt $c$ in comparison to control, indicating an impairment of mitochondrial function.

In conclusion, the present study demonstrated that POA may lead to persistent toxicity in L-02 cells. The mechanisms of POA-mediated hepatocellular toxicity potentially involve apoptosis via oxidative stress injury and impairment of mitochondrial function in L-02 cells. The alteration of mitochondrial function and oxidative stress may be the major cause for the activation of the caspase cascade that results in apoptosis in response to POA-induced hepatocellular toxicity. However, whether other mechanismsare associated withPOA-induced cytotoxicity remain to be further investigated.

\section{Acknowledgements}

The present study was supported by the National Marine Public Welfare Research Project of China (grant no. 201305017), the National Natural Science Foundation of China (grant no. 81573638), the Natural Science Foundation of Guangdong Province (grant nos. 2016A030313859 and 2017A030313666) and the Science Program for Overseas Scholar of Guangzhou University of Chinese Medicine (Torch Program; grant no. XH20150107).

\section{References}

1. Russmann S, Kullak-Ublick GA and Grattagliano I: Current concepts of mechanisms in drug-induced hepatotoxicity. Curr Med Chem 16: 3041-3053, 2009.

2. Gerets HH, Tilmant K, Gerin B, Chanteux H, Depelchin BO, Dhalluin $S$ and Atienzar FA: Characterization of primary human hepatocytes, HepG2 cells and HepaRG cells at the mRNA level and CYP activity in response to inducers and their predictivity for the detection of human hepatotoxins. Cell Biol Toxicol 28: 69-87, 2012.

3. O'Brien PJ, Irwin W, Diaz D, Howard-Cofield E, Krejsa CM, Slaughter MR, Gao B, Kaludercic N, Angeline A, Bernardi P, et al: High concordance of drug-induced human hepatotoxicity with in vitro cytotoxicity measured in a novel cell-Based model using high content screening. Arch Toxicol 80: 580-604, 2006.

4. Aggarwal BB, Sundaram C, Malani N and Ichikawa H: Curcumin: The Indian solid gold. Adv Exp Med Biol 595: 1-75, 2007.

5. Houbraken J, Frisvad JC and Samson RA: Fleming's penicillin producing strain is not Penicillium chrysogenum but $P$. rubens. IMA Fungus 2: 87-95, 2011.

6. Cragg GM and Newman DJ: Natural products: A continuing source of novel drug leads. Biochim Biophys Acta 1830 3670-3695, 2013.

7. Senni K, Pereira J, Gueniche F, Delbarre-Ladrat C, Sinquin C, Ratiskol J, Godeau G, Fischer AM, Helley D and Colliec-Jouault S: Marine polysaccharides: A source of bioactive molecules for cell therapy and tissue engineering. Mar Drugs 9: 1664-1681, 2011.
8. Sun YL, Bao J, Liu KS, Zhang XY, He F, Wang YF, Nong XH and Qi SH: Cytotoxic dihydrothiophene-condensed chromones from marine-derived fungus Penicillium oxalicum. Plata Med 79: 1474-1479, 2013

9. Zhang XY, Bao J, Wang GH, He F, Xu XY and Qi SH: Diversity and antimicrobial activity of culturable fungi isolated from six species of the South China Sea gorgonians. Microb Ecol 64: 617-627, 2012.

10. Cai Q, Wei J, Zhao W, Shi S, Zhang Y, Wei R, Zhang Y, Li W and Wang Q: Toxicity of Evodiae fructus on rat liver mitochondria: The role of oxidative stress and mitochondrial permeability transition. Molecules 19: 21168-21182, 2014.

11. Zhang JQ, Shen M, Zhu CC, Yu FX, Liu ZQ, Ally N, Sun SC, Li K and Liu HL: 3-Nitropropionic acid induces ovarian oxidative stress and impairs follicle in mouse. PLoS One 9: e86589, 2014.

12. Zhang XY, Bao J, Zhong J, Xu XY, Nong XH and Qi SH: Enhanced production of a novel cytotoxic chromone oxalicumone a by marine-derived mutant Penicillium oxalicum SCSIO 24-2. Appl Microbiol Biotechnol 97: 9657-9663, 2013.

13. Jacobson MD, Weil M and Raff MC: Programmed cell death in the animal development. Cell 88: 347-354, 1997.

14. Pirocanac EC, Nassirpour R, Yang M, Wang J, Nardin SR, Gu J, Fang B, Moossa AR, Hoffman RM and Bouvet M: Bax-induction gene therapy of pancreatic cancer. J Surg Res 106: 346-351, 2002.

15. Wilson MR: Apoptotic signal transduction: Emerging pathways. Biochem Cell Biol 76: 573-782, 1998.

16. Daniel PT, Wieder T, Sturm I and Schulze-Osthoff K: The kiss of death: Promises and failures of death receptors and ligands in cancer therapy. Leukemia 15: 1022-1032, 2001.

17. Itoh N, Yonehara S, Ishii A, Yonehara M, Mizushima S, Sameshima M, Hase A, Seto Y and Nagata S: The polypeptide encoded by the cDNA for human cell surface antigen fas can mediate apoptosis. Cell 66: 233-243, 1991.

18. Waring P and Müllbacher A: Cell death induced by the Fas/Fas ligand pathway and its role in pathology. Immunol Cell Biol 77: 312-317, 1999.

19. Certo M, Del Gaizo V, Nishino M, Wei G, Korsmeyer S, Armstrong SA and Letai A: Mitochondria primed by death signals determine cellular addiction to antiapoptotic BCL-2 family members. Cancer Cell 9: 351-365, 2006.

20. Yang J, Liu X, Bhalla K, Kim CN, Ibrado AM, Cai J, Peng TI, Jones DP and Wang X: Prevention of apoptosis by Bcl-2: Release of cytochrome c from mitochondria blocked. Science 275: 1129-1132, 1997.

21. Lanave C, Santamaria M and Saccone C: Comparative genomics: The evolutionary history of the Bcl-2 family. Gene 333: 71-79, 2004.

22. Hussain SM and Frazier JM: Cellular toxicity of hydrazine in primary rat hepatocytes. Toxicol Sci 69: 424-432, 2002.

23. Valko M, Jomova K, Rhodes CJ, Kuča K and Musílek K: Redoxand non-redox-metal-induced formation of free radicals and their role in human disease. Arch Toxicol 90: 1-37, 2016.

24. Farber JL, Kyle ME and Coleman JB: Mechanisms of cell injury by activated oxygen species. Lab Invest 62: 670-679, 1990.

25. Sinha K, Das J, Pal PB and Sil PC: Oxidative stress: The mitochondria-dependent and mitochondria-independent pathways of apoptosis. Arch Toxicol 87: 1157-1180, 2013.

26. Yao J, Jiang Z, Duan W, Huang J, Zhang L, Hu L, He L, Li F, Xiao Y, Shu B and Liu C: Involvement of mitochondrial pathway in triptolide-induced cytotoxicity in human normal liver L-02 cells. Biol Pharm Bull 31: 592-597, 2008.

27. Ramachandran A, Lebofsky M, Baines CP, Lemasters JJ and Jaeschke H: Cyclophilin d deficiency protects against acetaminophen-induced oxidant stress and liver injury. Free Radic Res 45: 156-164, 2011.

28. Haasio K, Koponen A, Penttilä KE and Nissinen E: Effects of entacapone and tolcapone on mitochondrial membrane potential. Eur J Pharmacol 453: 21-26, 2002.

29. Green DR and Reed JC: Mitochondria and apoptosis. Science 281: 1309-1312, 1998.

30. Urra FA, Cordova-Delgado M, Pessoa-Mahana H, RamirezRodriguez O, Weiss-Lopez B, Ferreira J and Araya-Maturana R: Mitochondria: A promising target for anticancer alkaloids. Curr Top Med Chem 13: 2171-2183, 2013. 